\title{
Characteristics of Volatile Organic Compounds during Different Pollution Periods in Winter in Yuncheng, a Typical City in North China
}

\author{
Qianzhuo Gao ${ }^{1}$, Yulong Yan ${ }^{1 *}$, Rumei Li ${ }^{1,2}$, Yang $\mathrm{Xu}^{1,2}$, Yueyuan Niu ${ }^{1}$, Chenglong Liu ${ }^{1}$, \\ Kai Xie', Zeiwei Chang ${ }^{1}$, Dongmei Hu${ }^{1}$, Zhiyong $\mathrm{Li}^{3}$, Lin Peng ${ }^{1}$ \\ ${ }^{1}$ MOE Key Laboratory of Resources and Environmental System Optimization, College of Environmental Science and \\ Engineering, North China Electric Power University, Beijing 102206, China \\ ${ }^{2}$ School for Energy, Power and Mechanical Engineering, North China Electric Power University, Beijing 102206, China \\ ${ }^{3}$ School of Environmental Science and Engineering, North China Electric Power University, Baoding 07100, China
}

\begin{abstract}
The composition characteristics and health risks of volatile organic compounds (VOCs) and their effects on secondary organic aerosol (SOA) during polluted and clean periods in winter 2018 for Yuncheng, a typical city in North China, were studied. The average concentration of VOCs was 2.3 times higher during the polluted period $\left(105.29 \mu \mathrm{g} \mathrm{m}^{-3}\right)$ than the clean period $\left(45.78 \mu \mathrm{g} \mathrm{m}^{-3}\right)$, whereas the average concentrations of the alkanes, alkenes, and aromatics were 3.4, 2.1, and 3.9 times higher, respectively, during the polluted period than the clean period. In addition, the VOC concentration was significantly influenced by meteorological conditions. Using positive matrix factorization (PMF), seven sources of atmospheric VOCs were identified, with the largest factors being vehicle emission (27.89\%), coal combustion (23.37\%), liquefied petroleum gas/natural gas evaporation (18.30\%), and industrial emission (15.51\%). Vehicle emission $(30.04 \%)$ was the primary contributor during the polluted period, whereas coal combustion $(33.53 \%)$ was the primary contributor during the clean period. The SOA formation potential (which almost exceeded $80 \%$ ) was influenced by industrial emission $(28.80 \%)$, solvent usage $(26.30 \%)$, and vehicle emission $(24.85 \%)$. Additionally, an assessment of the health risks of six aromatics based on the health risk exposure model of the United States Environmental Protection Agency revealed that the non-cancer risk was higher during the polluted period $\left(6.61 \times 10^{-2}\right)$ than the clean period $\left(2.20 \times 10^{-2}\right)$ but still below the Environmental Protection Agency (EPA) limit (1.00) and therefore negligible for the exposed population. However, the carcinogenic index of benzene $\left(2.85 \times 10^{-5}\right.$ to $\left.5 \times 10^{-5}\right)$ exceeded $10^{-6}$, suggesting a higher carcinogenic risk. Large-scale energy restructuring during recent years has sharply reduced coal combustion, but the VOC concentration has dramatically increased due to vehicle emission. Hence, regulating vehicle emissions is an effective strategy for controlling VOCs in Yuncheng.
\end{abstract}

Keywords: Volatile organic compounds; Source apportionment; Secondary organic aerosol formation potential; Health risk assessment; Pollution period.

\section{INTRODUCTION}

Volatile organic compounds, one of the important organic contaminants in the atmosphere, cause environmental pollution and are harmful to human health (Chang et al., 2019). Numerous VOC species, including benzene and ethylbenzene, have been confirmed as carcinogens and potentially toxic substances (Yan et al., 2015). Additionally, VOCs act as precursors of photochemically formed secondary pollutants such as secondary organic aerosol (SOA), which may contribute to haze days (Sun et al., 2016). Understanding

\footnotetext{
* Corresponding author.

Tel.: +861061772891

E-mail address: yanyulong@yeah.net
}

VOC sources and the associated risk to human health is fundamental for establishing measures to reduce VOC emission into the environment.

In recent years, frequent haze events in winter in northern China have caused widespread concern regarding its effects on human health and atmospheric visibility (Liu et al., 2016a; Li et al., 2015; Zheng et al., 2017; Hu et al., 2018). Studies have indicated that haze days are largely affected by SOA formation and poor meteorological conditions (Guo et al., 2014; Zheng et al., 2015). As an important precursor of SOA, high VOC concentrations may largely contribute to $\mathrm{PM}_{2.5}$ generation in haze pollution. Liu et al. (2016) found that the VOC concentration in Beijing was obviously higher during haze-fog days $\left(461.61 \mu \mathrm{g} \mathrm{m}^{-3}\right)$ than during clean days $\left(208.63 \mu \mathrm{g} \mathrm{m}^{-3}\right)$. Studying VOCs in haze episodes is helpful for understanding VOC characteristics and providing guidance for VOC control strategies. In a recent study, Cai 
et al. (2010) used the PMF to reveal that VOCs in pollution days in Shanghai were derived from industrial sources (29\%), vehicle emission $(25 \%)$, solvent usage $(17 \%)$, liquefied petroleum gas (LPG) and gasoline evaporation (15\%), biomass/biofuel burning (9\%), and coal combustion (7\%). High levels of VOCs, especially toxic species such as benzene, toluene, ethylbenzene and xylene (BTEX), cause health risks in exposed people (Yan et al., 2015). Dutta et al. (2009) investigated the health risks of BTEX in India; they found that high levels of VOCs were mainly derived from transportation sources, and the risk of carcinogenesis can reach $6.1 \times 10^{-5}$, which was 1.9 times that of the background point. In Guangzhou, the health risk of BTEX was $5.34 \times$ $10^{-5}$, which was much higher than the recommended level of $1 \times 10^{-6}$ (Li et al., 2015).

Based on the potential harm of VOCs in haze pollution, few studies have investigated the ability of VOCs to form SOA and the effects on public health under different pollution conditions in North China. In this study, characteristics, source contribution, SOA formation potential (SOAfp), and health risk assessment of VOCs were analyzed during pollution and clean periods in Yuncheng. The source of VOCs was identified using the PMF, and combining the fractional aerosol coefficient (FAC) method, we also calculated the SOAfp of each VOC source. In addition, we use the health risk exposure model of the United States Environmental Protection Agency to estimate the potential risks of BTEX in exposed people. Three main objectives were to determine the major sources of VOCs by comparing the proportion of sources in pollution and clean periods, to calculate SOAfp and determine the qualitative relationship between VOCs and $\mathrm{PM}_{2.5}$, and to explore the sources and compounds with higher contribution to public health risks.

\section{MATERIALS AND METHODS}

\section{Sampling Sites}

Yuncheng is located in the south of Shanxi Province, covering $13,968 \mathrm{~km}^{2}$ with a population of approximately $5,600,000$. With rapid development in economy and sharp increase in energy consumption, $\mathrm{PM}_{2.5}$ in Yuncheng is at a higher level than that in other cities in Shanxi in North China (Fig. 1). In this study, sampling was conducted from January 20 to 24, 2018. The sampling points were located on the top of Yuncheng Middle School $\left(35.05^{\circ} \mathrm{N}, 111.03^{\circ} \mathrm{E}\right), 25 \mathrm{~m}$ above the ground level, and the sampling site was close to the central urban area, which includes residential, commercial, and office mixed areas and reflect the regional pollution level of Yuncheng. According to the air quality index (AQI) value, the VOC sampling time was divided into the polluted period with AQI $>200$ (January 20-22) and clean period with AQI < 200 (January 23-24). VOCs were sampled from 06:00 to 20:00 (at a 2-h interval) using SUMMA canisters (Silonite ${ }^{\circledR}$ Canisters; Entech Instruments Inc., CA, USA).

\section{Chemical Analysis}

In this study, gas samples were preprocessed using a Model 7100 VOC preconcentrator (Entech Instruments Inc., USA) and analyzed through a gas chromatographer equipped with a mass-selective detector (7890A GC/5975C MSD/FID; Agilent Technologies, USA). Firstly, gas samples (300 mL) were drawn into a cold trap Module 1 . The samples were cooled at $-160^{\circ} \mathrm{C}$ and desorbed at $10^{\circ} \mathrm{C}$. $\mathrm{N}_{2}, \mathrm{O}_{2}$, and some argon (Ar) were separated on the cold trap Module 1. Secondly, the samples desorbed from Module 1 were concentrated at Module 2 at $-40^{\circ} \mathrm{C}$. $\mathrm{CH}_{4}, \mathrm{CO}_{2}$, some water, and the rest of Ar were separated from the cold trap

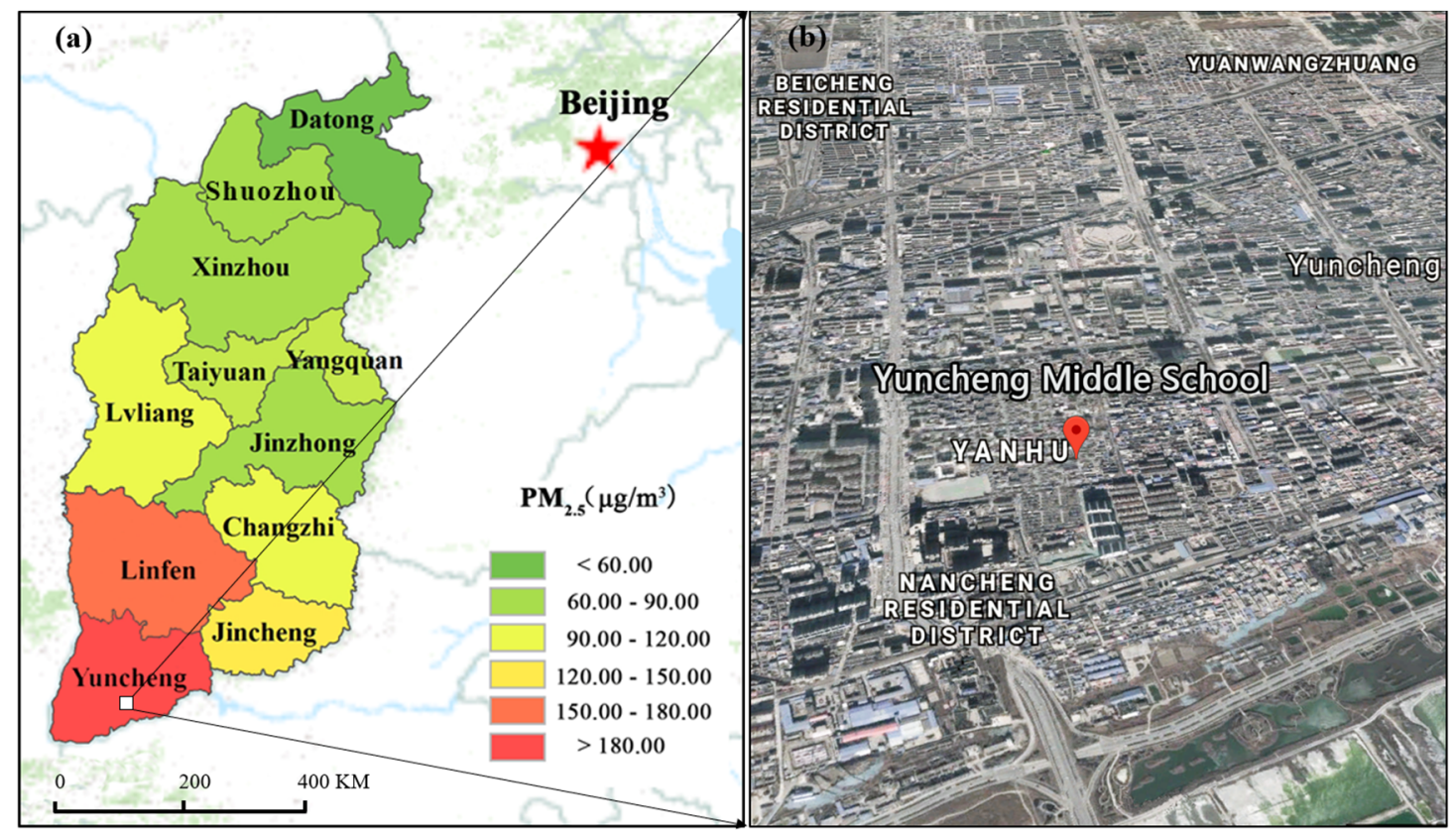

Data Source: YunCheng's Environmental Protection Bureau, January 2018

Fig. 1. (a) The spatial distribution of $\mathrm{PM}_{2.5}$ in Yuncheng and surrounding cities during the whole observation. (b) The sampling site was in Yuncheng Middle School. 
Module 2. Third, the samples were frozen in an empty capillary column (trap Module 3 ) at $-150^{\circ} \mathrm{C}$. After being frozen, the samples from empty capillary column were heated and vaporized quickly. All target species were transferred under high-purity $(99.999 \%)$ helium to the DB-1 capillary column $(60 \mathrm{~m} \times 0.32 \mathrm{~mm} \times 1.0 \mathrm{~mm}$; Agilent Technologies, USA) for separation. Then, $\mathrm{C}_{2}-\mathrm{C}_{3}$ hydrocarbons were separated on a PLOT-Q column $(30 \mathrm{~m} \times 0.32 \mathrm{~mm} \times 2.0 \mathrm{~mm}$; Agilent Technologies, USA) and detected using an FID, whereas other species of $\mathrm{C}_{4}-\mathrm{C}_{12}$ hydrocarbons were trapped in the passivated empty capillary column and detected using an MSD. To ensure data validity, quality assurance and control (QA/QC) procedures were performed for the certification of all samples, and the QA/QC procedures performed in this study followed those by Yan et al. (2015).

\section{Data Analysis \\ SOAfp}

SOAfp represents the maximum propensity for VOCs to form SOA. In this study, $\mathrm{FAC}_{\mathrm{i}}$ was used to estimate SOAfp directly. The equation is as follows:

$\mathrm{SOAfp}_{\mathrm{i}}=\mathrm{VOCs}_{\mathrm{i}} \times \mathrm{FAC}_{\mathrm{i}}$

where SOAfp $\mathrm{i}_{\mathrm{i}}$ is the SOAfp of VOC species $\mathrm{i}, \mu \mathrm{g} \mathrm{m} \mathrm{m}^{-3}$; VOCs $0_{i}$ is the initial concentration of VOC species $i$ calculated by Eq. (2), $\mu \mathrm{g} \mathrm{m}^{-3}$; and $\mathrm{FAC}_{\mathrm{i}}$ is the $\mathrm{SOA}$-generating coefficient of VOC species $i$.

$$
\mathrm{VOCs}_{\mathrm{ti}}=\operatorname{VOCs}_{\mathrm{i}}\left(1-\mathrm{F}_{\mathrm{VOCri}}\right)
$$

where $\mathrm{VOCS}_{\mathrm{ti}}$ is the concentration of VOC species $\mathrm{i}$ measured in this study, $\mu \mathrm{g} \mathrm{m}^{-3}$. F FoCri is the reacted percentage of VOC species i. Among them, $\mathrm{FAC}_{\mathrm{i}}$ and $\mathrm{F}_{\mathrm{VOCri}}$ are provided by Grosjean et al. (1989) from multiple smoke box experiments, which could estimate the SOA concentration from measured VOCs and reflect the contribution of SOA precursors. The equation is based on the following assumptions: SOA is only generated during daytime (08:00 $17: 00)$, and the removal of VOCs is governed by the reaction with $\mathrm{OH}$ radicals.

\section{$P M F$}

The PMF model is widely used for analyzing the source apportionment of VOCs in the atmosphere (Yan et al., 2017; Hui et al., 2018), especially suitable for the consecutive collecting of VOC samples like in this study (Norris et al., 2014). PMF is an advanced receptor model that decomposes a matrix of sample data $(\mathrm{X})$ into two matrices, the source contribution matrix $(\mathrm{G})$ and the source matrix $(\mathrm{F})$, the mass amount of a species can be calculated from the contribution of sources to samples and the species profile of each source, as shown in Eq. (3) (Norris et al., 2014):

$$
x_{i j}=\sum_{k=1}^{p} g_{i k} f_{i k}+e_{i j}
$$

where $x_{i j}$ is the concentration of $j^{\text {th }}$ species measured in the $i^{\text {th }}$ sample, $g_{i k}$ is the contribution of the $k^{\text {th }}$ source to the $i^{\text {th }}$ sample, $\mathrm{f}_{\mathrm{kj}}$ is the fraction of $\mathrm{j}^{\mathrm{th}}$ species from the $\mathrm{k}^{\text {th }}$ source, $\mathrm{e}_{\mathrm{ij}}$ is the residual for each sample/species, and $\mathrm{p}$ is the total number of the sources.

Eq. (4) usually leads to uncertainty due to the error fraction of species concentrations and the method detection limit (MDL; ppbv) (Norris et al., 2014). The PMF analysis minimizes the objective function $\mathrm{Q}$ based on the uncertainties:

$$
Q=\sum_{i=1}^{n} \sum_{j=1}^{m}\left[\frac{x_{i j}-\sum_{k=1}^{p} g_{i k} f_{k j}}{u_{i j}}\right]^{2}
$$

where $n$ and $m$ is the number of samples and the number of VOC species, respectively, and $\mathrm{u}_{\mathrm{ij}}$ is uncertainty of the $\mathrm{j}^{\text {th }}$ species measured in the $\mathrm{i}^{\text {th }}$ sample.

In the PMF analysis, the uncertainties of the input datasets were calculated using Eqs. (5) and (6) (Norris et al., 2014). If the VOC concentration (Conc.) is less than MDL, Eq. (5) is adopted. Otherwise, Eq. (6) is adopted:

$$
\begin{aligned}
& U n c=\frac{5}{6} \times M D L \\
& U n c=\sqrt{(\text { Error Fraction } \times \text { concentration })^{2}+(0.5 \times M D L)^{2}}
\end{aligned}
$$

We used the USEPA PMF 5.0 model to perform source apportionment for VOCs in the atmosphere. The principles of PMF were as follows: Species with high proportions of missing samples were excluded, and data below the MDL were substituted with $0.5 \times$ MDL; species with high reactivity were excluded because they were rapidly consumed in the atmosphere (exclude some trace compounds, such as isoprene); and species with a lower mixing ratio should be avoided because they were not important tracers of VOC sources. Eventually, considering the fundamental assumption of nonreactivity or mass conservation of the PMF model, 38 VOC species were identified and quantified for source apportionment in this study.

\section{Health Risk Assessment}

To identify the effects of pollution sources on human health, we used the Integrated Risk Information System (IRIS) by USEPA to estimate the health risk of specific VOCs in this study. The risk of inhalation of non-carcinogenic and carcinogenic VOCs was assessed using the following equation:

$$
\mathrm{EC}=(\mathrm{CA} \times \mathrm{ET} \times \mathrm{EF} \times \mathrm{ED}) / \mathrm{AT}
$$

where EC $\left(\mu \mathrm{g} \mathrm{m}^{-3}\right)$ represents inhalation exposure concentrations, where CA represents the concentration of pollutants, $\mu \mathrm{g} \mathrm{m}^{-3}$. ET represents the exposure time, $24 \mathrm{~h} \mathrm{~d}^{-1}$. EF represents the exposure frequency, $365 \mathrm{~d} \mathrm{y}^{-1}$. ED represents the exposure duration $(70 \mathrm{y})$. AT represents the 
average exposure time, $70 \times 365 \times 24 \mathrm{~h}$. Based on Eq. (1), the sustained exposure concentration is assessed.

In this study, carcinogenic $(\mathrm{R})$ and non-carcinogenic risks (HQ) of all risk-posing VOC species were estimated using Eqs. (8), (9), (10), respectively:

$\mathrm{R}=\mathrm{EC} \times \mathrm{IUR}$

$\mathrm{HQ}=\mathrm{EC} /(\operatorname{RfC} \times 1000)$

$\mathrm{HI}=\sum \mathrm{HQ}$

where $\mathrm{R}$ is the estimated inhalation cancer risk. IUR $\left(\mathrm{m}^{3} \mu \mathrm{g}^{-1}\right)$ represents the inhalation unit risk, and data are from U.S. EPA's IRIS. Normally, cancer risks no higher than $1 \times$ $10^{-6}$ was regarded as acceptable. Where HQ is the non-cancer risk hazard quotient (HQ) of specific VOCs, RfC $\left(\mathrm{mg} \mathrm{m}^{-3}\right)$ represents chronic reference concentration, $\mathrm{mg} \mathrm{m}^{-3}$. Where HI represents the sum of HQs of several pollutants. Namely, if the value of $\mathrm{HQ}$ or $\mathrm{HI}$ is below 1 , there is no chronic toxicity. On the contrary, if the value of HQ exceeds 1 , chronic toxicity will occur after long-term exposure.

\section{RESULTS AND DISCUSSION}

\section{Overall Level of VOCs in Yuncheng}

The concentrations of VOCs were determined in pollution, clean, and whole observation periods in Yuncheng (Table 1). The total concentration of VOCs in the atmosphere was $87.70 \mu \mathrm{g} \mathrm{m}^{-3}$, and 47 major VOC species were measured, including 26 alkanes, 10 alkenes, 11 aromatics, and 1 alkyne. Alkanes and aromatics were the most abundant species, accounting for $61.04 \%$ and $22.84 \%$ of VOCs, respectively. Alkyne contained acetylene only but represented $6.30 \%$ of VOCs. In addition, among VOCs, 5 compounds, namely propane $\left(13.55 \mu \mathrm{g} \mathrm{m}^{-3}\right), n$-butane $\left(12.48 \mu \mathrm{g} \mathrm{m}^{-3}\right)$, benzene $\left(8.89 \mu \mathrm{g} \mathrm{m}^{-3}\right)$, ethane $\left(5.92 \mu \mathrm{g} \mathrm{m}^{-3}\right)$, and acetylene $\left(5.52 \mu \mathrm{g} \mathrm{m}^{-3}\right)$, were the dominant species, which accounted for $52.89 \%$ of VOCs. The level of VOCs in the polluted period $\left(105.29 \mu_{\mathrm{g} \mathrm{m}^{-3}}\right)$ was 2.3 times that in the clean period $\left(46.03 \mu \mathrm{g} \mathrm{m}^{-3}\right)$. Alkanes showed the highest concentration, and VOC composition characteristics were basically same during the whole observation period, indicating that emission sources may be consistent in pollution and clean periods.

Comparisons of VOC level in winter in Yuncheng and other northern and southern cities in China are shown in Fig. 2. The VOC concentration during the observation period was higher in Yuncheng than in winter in Beijing $\left(66.90 \mu \mathrm{g} \mathrm{m}^{-3}\right)$, Tianjin $\left(39.40 \mu \mathrm{g} \mathrm{m}^{-3}\right)$, and Wuhan $\left(44.87 \mu \mathrm{g} \mathrm{m}^{-3}\right)$ and was lower to that in winter in Jincheng $\left(93.34 \mu \mathrm{g} \mathrm{m}^{-3}\right)$ (Liu et al., 2016b; Lyu et al., 2016; Wei et al., 2018; Yang et al., 2019), which indicated that VOC concentration in Yuncheng was at a relatively middle level among northern cities. Concentrations of alkanes and VOCs in Yuncheng were prominently higher than those in the southern Chinese cities (An et al., 2011; Xu et al., 2015; Liu et al., 2011; Song et al., 2019b). Alkanes and aromatics in Yuncheng were higher than other cities, such as Beijing, Tianjin and Wuhan (Liu et al., 2016b; Lyu et al., 2016; Wei et al., 2018). Barletta et al. (2005) showed that coal combustion in winter leads to emit VOCs with highcontent alkanes and aromatics. In addition, a high demand for coal combustion in winter may be a key factor for VOC pollution in Yuncheng.

\section{Variation of VOCs in Different Pollution Periods}

Daily variations of wind speed, relative humidity, temperature $(\mathrm{T})$, air quality index (AQI), VOC species, and VOCs are shown in Fig. 3. We observed that the proportion of alkanes $(61.04 \%)$ and aromatics $(22.84 \%)$ was higher in the whole observation period. Nelson et al. (1984) reported that the high concentration of alkanes and aromatics highlighted the strong effects of coal combustion. The diurnal variation in the VOC concentration was consistent with AQI. Poor meteorological conditions may lead to the accumulation of pollutants, higher AQI, and excessive VOCs. During the polluted period, the average wind speed was $1.71 \mathrm{~m} \mathrm{~s}^{-1}$. The concentrations of VOCs, AQI, and $\mathrm{PM}_{2.5}$ were 105.29, 286, and $237 \mu \mathrm{g} \mathrm{m}^{-3}$, respectively. On January 23, the wind shifted from north to south, with a temporarily increasing wind speed $\left(11.19 \mathrm{~m} \mathrm{~s}^{-1}\right)$, which rapidly reduced the concentration of VOCs in the atmosphere to $43.87 \mu \mathrm{g} \mathrm{m}^{-3}$. The concentrations of AQI and $\mathrm{PM}_{2.5}$ were 124 and $94 \mu \mathrm{g} \mathrm{m}^{-3}$, respectively.

Snowfall occurring on January 24 was also responsible for the removal of pollutants, including VOCs. Fries et al. (2008) revealed that gas and particle scavenging by snow/ice have the potential to significantly contribute to the deposition of volatile organic compounds by washing out the aerosol particles. The concentration of VOCs decreased significantly after snowfall (Fig. 3). Because Yuncheng belongs to a basin type, the accumulation of pollutants is easy due to poor meteorological conditions such as low wind speed and high humidity, whereas the wind speed increases, pollutants rapidly cleared in a relatively short time. VOC concentrations during sampling time have a reverse tendency with wind speed during, especially while pollution happened and ended (Fig. 3).

\section{Diurnal Variation during Pollution and Clean Periods}

The diurnal variation characteristics of VOCs observed in

Table 1. VOC concentrations measured in pollution, clean period and whole observation in Yuncheng.

\begin{tabular}{llll}
\hline \multirow{2}{*}{ Species } & Polluted period & Clean period & Whole observation \\
\cline { 2 - 4 } & Mean \pm S.D. $\left(\mu \mathrm{g} \mathrm{m}^{-3}\right)$ & Mean \pm S.D. $\left(\mu \mathrm{g} \mathrm{m}^{-3}\right)$ & Mean \pm S.D. $\left.(\mu \mathrm{g} \mathrm{m})^{-3}\right)$ \\
\hline Alkanes & $64.40 \pm 20.30$ & $27.61 \pm 8.22$ & $53.5 \pm 25.36$ \\
Alkenes & $9.82 \pm 4.87$ & $5.78 \pm 1.88$ & $8.80 \pm 4.79$ \\
Alkynes & $6.37 \pm 2.56$ & $3.53 \pm 1.23$ & $2.60 \pm 5.52$ \\
Aromatics & $24.69 \pm 9.63$ & $9.10 \pm 2.89$ & $20.02 \pm 11.12$ \\
VOCs & $105.29 \pm 37.37$ & $46.03 \pm 14.22$ & $87.70 \pm 45.87$ \\
\hline
\end{tabular}




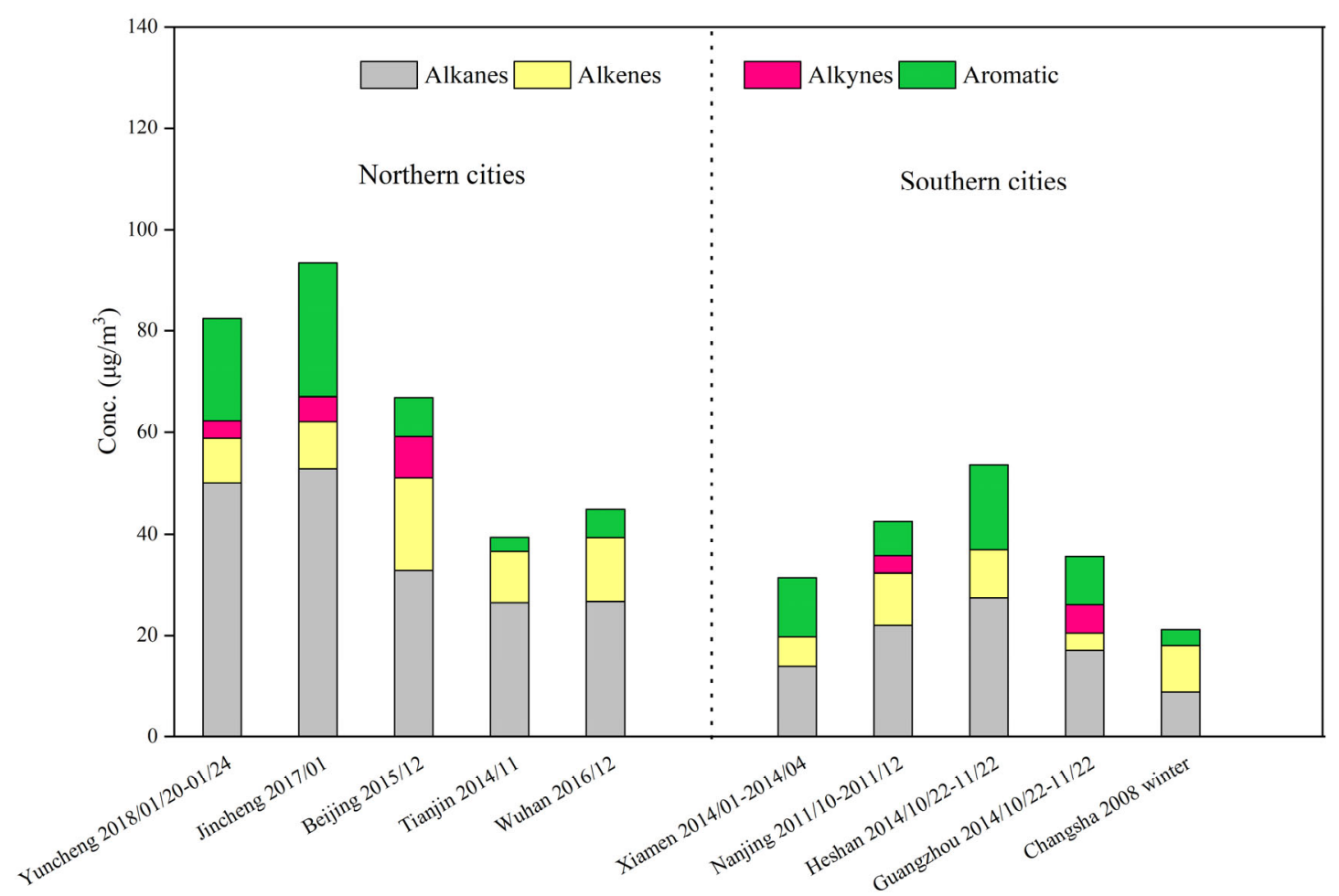

Fig. 2. Comparison of the ambient levels of VOCs among the study area and other cities.

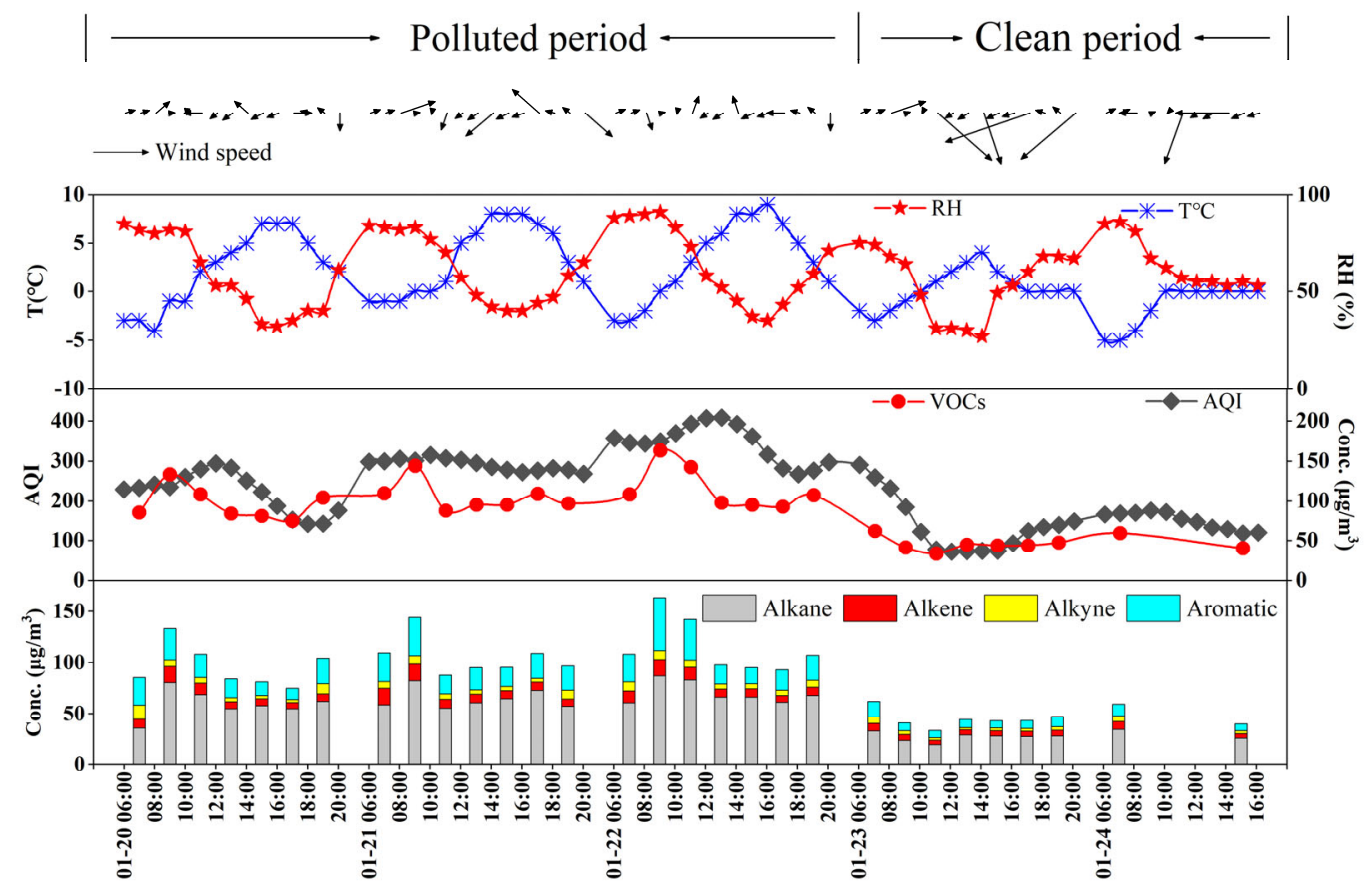

Fig. 3. Diurnal variation of the concentration of VOCs, AQI and meteorological conditions during whole observation.

this study were the same as those also reported in winter in Jincheng, a city just located near Yuncheng (Yang et al., 2018), which revealed that the level of VOCs increased significantly at 08:00-10:00 and 18:00-20:00. Compared with the clean period, VOCs had obvious diurnal variation during the polluted period, as illustrated in Fig. 4. Na et al. (2001) demonstrated that the diurnal variation of VOCs was influenced by relevant VOC source strength, photochemical reaction intensity, and diffusion conditions. The peak traffic of Yuncheng was at 08:00, which was consistent with the timing of increases in the VOC concentration. In addition, VOCs were less consumed in the atmosphere because of weak light intensity in the morning, resulting in a high concentration. In the afternoon, VOCs were obviously reduced 

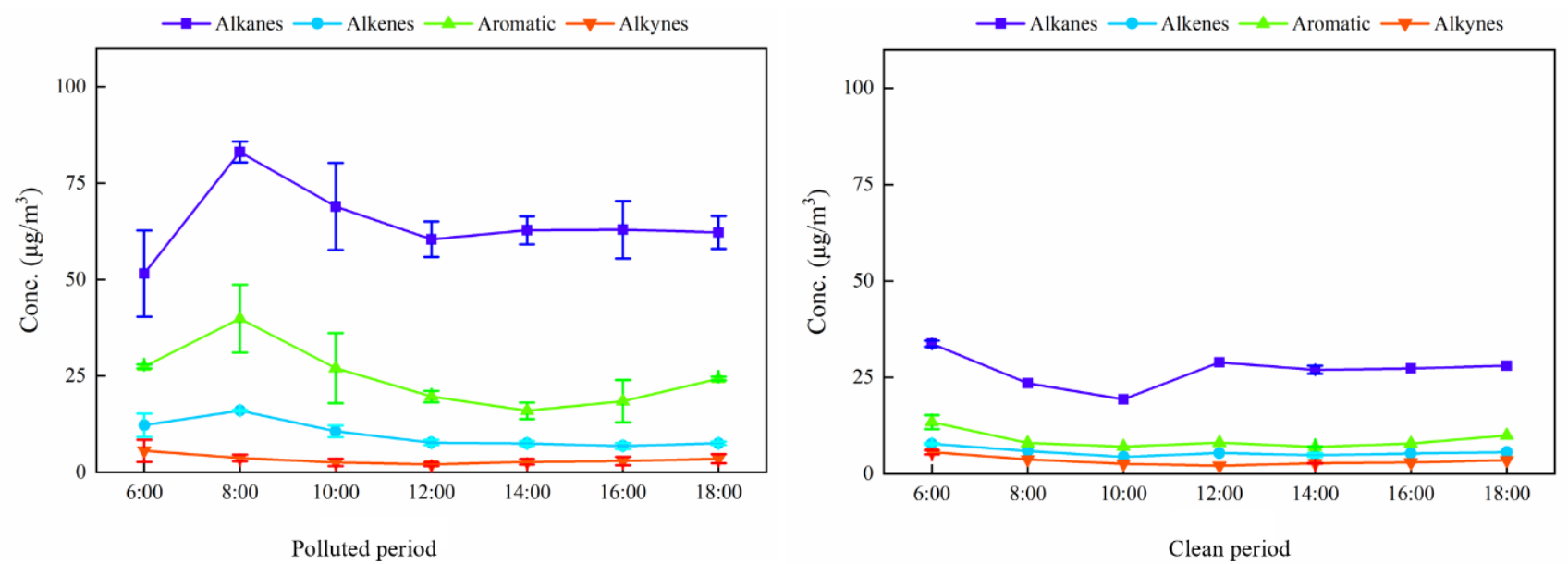

Fig. 4. Diurnal variation of VOCs during the observation: polluted period vs. clean period in Yuncheng.

by the increase in temperature and intense photochemical reactions, accelerating the conversion of VOCs into other substances.

\section{Comparison of VOC Compounds in Different Periods}

By studying VOC dominant species, we will be able to clearly understand which sources require controlling during heavy pollution to some extent. Thus, the top $15 \mathrm{VOC}$ species were compared in pollution and clean periods. The composition of the top 15 species was basically consistent in pollution and clean periods (Fig. S1). Na et al. (2004) mentioned that aromatics in the atmosphere were mainly derived from coal combustion and solvents. Wang et al. (2017) found that vehicle sources emit more alkenes, such as ethene and propene. The high proportion of aromatics and alkynes in Yuncheng may be associated with the increased demand for coal combustion in winter and the rapid growth in vehicle ownership in the past few years. Propane, $n$-butane, and benzene reached a high level in the polluted period, which was much higher than that in the clean period. Song et al. (2019a) showed that propane, $n$-butane, and benzene were typical tracers of vehicle emission, which indicated vehicle source emission was significantly increased in the polluted period.

\section{Source Analysis}

Diagnostic Ratios

Diagnostic ratios were used to make simple identification and judgments on VOC sources. The $\mathrm{B} / \mathrm{T}$ ratio is commonly used to identify the traffic source (Ho et al., 2004; Bruno et al., 2006; Lokesh et al., 2015). In this study, the $\mathrm{B} / \mathrm{T}$ ratio was observed to be $0.35-0.68$, which was consistent with that reported in Beijing (Wang et al., 2012), demonstrating that vehicle emission might be the main VOC source. In addition, the ratios of propane and $n$-butane to acetylene were used to determine the contributions of LPG leakage (Lai et al., 2009). In this study, the ratios of propane and $n$-butane to acetylene were 3.08 and 2.89 , respectively, during the polluted period, which was above the observation levels in Guangzhou (1.2 and 0.6, respectively; Zhang et al., 2013). This phenomenon suggested that LPG/natural gas (NG) evaporation may have a higher contribution during the polluted period in the atmosphere in Yuncheng.

\section{PMF Analysis}

In this study, source apportionment was conducted based on PMF 5.0. There was a good correlation $\left(\mathrm{R}^{2}=0.96\right)$ between the observed concentration and the simulated concentration by PMF, which showed the source analysis results could explain VOC pollution very well in Yuncheng. Seven possible VOC sources were identified, namely vehicle emission, coal combustion, LPG/NG, industrial sources, gasoline evaporation, solvent usage, and biogenic emission. The percentage contribution of the source characteristics is shown in Fig. S2.

Factor 1 was identified as the solvent usage source because of the high proportion of aromatics species, such as ethylbenzene $(40.58 \%), m$-xylene $(63.39 \%)$, and $p$-xylene $(73.97 \%)$, which are typical tracers of solvent usage (Yuan et al., 2010). Factor 2 was characterized by high percentages of $\mathrm{C}_{3}-\mathrm{C}_{6}$ alkanes (propane $(31.85 \%)$, isopentane $(27.11 \%)$, and 2 -methylpentane $(65.45 \%))$, and a few alkenes were closely related to vehicle emission; these findings are the same as those in previous studies (Grosjean et al., 1989; Cui et al., 2018; Deng et al., 2018). Factor 3 was distinguished by a significant percentage of isoprene $(80.91 \%)$. Because isoprene is an indicator of biogenic emission (Kesselmeier et al., 1989), Factor 3 was mainly attributed to biogenic sources. Factor 4 was characterized by high percentages of $\mathrm{C}_{5}-\mathrm{C}_{7}$ alkanes, especially isopentane $(50.90 \%)$ and $2,3-$ dimethyl-butane $(50.31 \%)$. Isopentane is a typical tracer of volatile gasoline (Liu et al., 2008; Eleonora et al., 2008). Therefore, this factor was identified as gasoline evaporation. Factor 5 was identified by a high percentage of ethane (74.29\%), ethene $(63.09 \%)$, and acetylene $(41.64 \%)$. Those species were all closely related to coal combustion (Zheng et al., 2018). Thus, Factor 4 was likely derived from coal combustion. Factor 6 presented the main components from propane $(34.10 \%), n$-butane $(53.67 \%)$, and $n$-hexane $(36.28 \%)$. McCarthy et al. (2013) revealed that propane and $n$-butane are the most abundant species in LPG/NG. LPG/NG was the third largest source because LPG has been widely used as a 
new energy source in North China Plain in the past few years. Thus, Factor 6 was suggested as the source of LPG/NG. Factor 7 was characterized by high values of $\mathrm{C}_{6}-\mathrm{C}_{9}$ alkanes and BTEX compounds (Hui et al., 2019), such as $n$-nonane $(54.10 \%)$, ethylbenzene (54.16\%), 1,3,5-trimethyltoluene (54.91\%), 1,2,4-trimethyltoluene $(66.92 \%)$, and 1,2,3trimethyltoluene $(59.44 \%)$. Therefore, Factor 7 was identified as industrial emission.

The source contributions to VOCs during the whole observation period, polluted period, and clean period are given in Fig. 5, which revealed that vehicle emission were the largest contributors in the polluted period (responsible for $29.04 \%$ of VOCs), followed by coal combustion source (21.56\%), LPG/NG (19.46\%), industrial sources (16.25\%), gasoline evaporation $(6.51 \%)$, solvent usage $(5.10 \%)$, and biogenic emission $(2.08 \%)$. However, the proportions of vehicle emission decreased sharply in the clean period (16.75\%) and industrial sources slightly reduced (11.88\%). During January 20-22 in 2018 of sampling period, Yuncheng issued heavy atmospheric pollution warning announcement to reduce pollutant emission, including VOCs (http://shanxi.si na.com.cn/news/report/2018-01-19/detail-ifyqtwzu6025167. shtml). The contribution of industrial emissions to VOCs in the atmosphere was gradually reduced, mainly due to the industrial production limit and implement the intermittent production of industrial, which was mandatory demanded by the announcement mentioned above. The contribution of LPG/NG to VOCs stabilized at a high degree in the whole observation period, accounting for $16.22-19.46 \%$ of VOCs at Yuncheng, which may be because LPG has been encouraged as a major clean fuel for cooking and heating in recent years. Therefore, we speculated that vehicle emission, coal combustion, and LPG/NG were the main contributors in Yuncheng during the whole observation period, which was consistent with the diagnostic ratios. The result suggested that restricting the emission of these three sources can effectively reduce VOC levels. With the full implementation of the "coal-to-gas" and "coal-to-electric" project in Yuncheng, coal used for combustion had decreased sharply from 2015, especially for residential combustion. In the winter of 2018, the coverage of centralized heat supply had increased to over 90\% in Yuncheng (https://www.yuncheng.gov.cn/article/18/ 06/36365.shtml), which would significantly reduce burned coal for decentralized and extensive heating. This would also cause less emission of pollutants, especially VOCs, a product of incomplete coal combustion. In addition, centralized heat supply was established in many northern cities, with an annual reduction of 74 million tons of coal in recent years (http://www.mee.gov.cn). In contrast to coal combustion, the number of vehicles increased gradually. In this study, the number of vehicles in Yuncheng increased to 1.15 million in 2018, with a continuous growth rate of $6.48 \%$ (https://www.yuncheng.gov.cn/article/19/04/56225.shtml).

The increase in the vehicle population significantly increased VOC emission from vehicle direct exhaust and gasoline volatilization. From the result of VOC source apportionment in Yuncheng, the contribution of vehicle emission exceeded that of coal combustion in polluted period, which reflected the situation of variation of atmospheric pollution in this northern city in China. Thus, controlling vehicle emission is a key to reduce atmospheric VOCs in this northern Chinese city, which should be a priority in environmental management.

\section{Apportionment of VOC Sources to SOAfp}

Yang et al. (2019) reported that through a photochemical reaction of VOCs, SOAfp can be a remarkable contributing factor to haze events in winter. The contribution of aromatics in the top 10 species to total SOAfp was $94.35 \%$ (Table 2). Toluene was the largest contributor to ambient SOA, contributing $31.28-31.35 \%$. In addition, aromatics were the major component of SOAfp, accounting for 95.96-97.21\%. PMF model results indicated solvent usage (40.17\%) and industrial emission $(30.37 \%)$ were the main sources contributing to aromatic in the whole period. Therefore, the main step to reduce SOA in the atmosphere was to control the solvent usage and industrial emission.

Daily variations of SOAfp, VOC, and $\mathrm{PM}_{2.5}$ concentrations are displayed in Fig. S3(a). SOAfp peaked at 06:00-08:00 in both the pollution and clean periods. The determined SOAfp values were $30-240 \mu \mathrm{g} \mathrm{m}^{-3}$ during the whole observation period, with an average of $120 \mu \mathrm{g} \mathrm{m}^{-3}$, which was higher than that reported in the Beijing haze episode, where the average level of SOAfp was $50 \mu \mathrm{g} \mathrm{m}^{-3}$ (Han et al., 2015). However, SOAfp obtained through the FAC method showed trends quite similar to VOC variation, illustrating the key role of VOC levels in SOAfp. However, the time change trend of

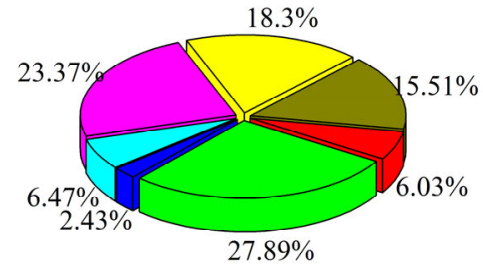

Whole observation

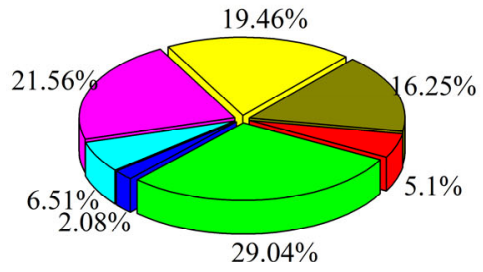

Polluted period

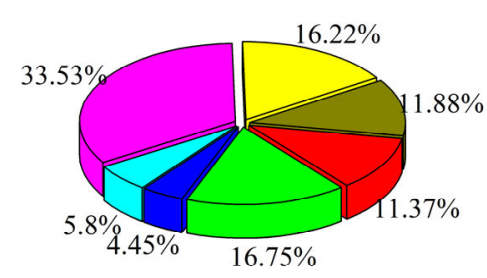

Clean period

$\begin{array}{ll}\square \text { Solvent Usage } & \square \text { Vehicle emission } \\ \text { Coal Combustion } & \text { Biogenic emission } \square \text { Gasoline evaporation } \\ & \square \text { LPG/NG }\end{array}$

Fig. 5. Source contributions to the VOC concentration in the PMF model during different pollution periods. 
Table 2. The top 10 SOAfp species during pollution and clean periods.

\begin{tabular}{llllll}
\hline \multirow{2}{*}{ VOCs species } & \multicolumn{2}{c}{ Polluted period } & \multicolumn{2}{c}{ Clean period } \\
\cline { 2 - 3 } \cline { 5 - 6 } & SOAfp $\left(\mu \mathrm{g} \mathrm{m}^{-3}\right)$ & Contribution $(\%)$ & & SOAf $\left(\mu \mathrm{g} \mathrm{m}^{-3}\right)$ & Contribution (\%) \\
\hline Toluene & 33.07 & 31.35 & 12.63 & 31.28 \\
Benzene & 24.66 & 23.37 & 8.33 & 20.62 \\
$m$-Xylene & 13.43 & 12.74 & 1.22 & 10.45 \\
1,3,5-Trimethybenzene & 2.57 & 2.44 & 3.11 & 2.83 \\
$p$-Xylene & 6.40 & 6.07 & 3.40 & 7.70 \\
Ethylbenzene & 7.41 & 7.03 & 2.74 & 8.40 \\
$o$-Xylene & 6.80 & 6.45 & 1.00 & 2.48 \\
Methylcyclohexane & 2.71 & 2.57 & 1.05 & 2.60 \\
1,2,4-Trimethylbenzene & 3.34 & 3.16 & 1.14 & 2.82 \\
1,2,3-Trimethylbenzene & 2.15 & 2.03 & 38.77 & 95.96 \\
Sum of top 10 & 102.55 & 97.21 & & \\
\hline
\end{tabular}

SOAfp and VOCs was $2-3 \mathrm{~h}$ earlier than the change trend of $\mathrm{PM}_{2.5}$, indicating that SOA and VOC undergo complex multiphase physicochemical processing for the formation of $\mathrm{PM}_{2.5}$ (Zhang et al., 2016). In the whole observation period, alkanes and alkenes did not contribute significantly to SOAfp, with the relative contributions of $0.94 \%$ and $1.90 \%$, respectively, whereas aromatics contributed $97.16 \%$ to SOAfp (Fig. S3(b)). During the polluted period, aromatics increased by $52.93 \%$ at $06: 00-08: 00$ on January 22 , and correspondingly, SOAfp rapidly increased from $107.10 \mu \mathrm{g} \mathrm{m}^{-3}$ to $227.04 \mathrm{\mu g} \mathrm{m}^{-3}$. Moreover, SOAfp significantly reduced from $100.97 \mathrm{\mu g} \mathrm{m}^{-3}$ to $32.68 \mu \mathrm{g} \mathrm{m}^{-3}$ as the concentration of VOCs decreased in the clean period. These results indicated that aromatics were the major contributors to SOA in the atmosphere, and identifying the aromatics emission source is important.

A strong correlation existed between SOAfp and VOCs $\left(\mathrm{R}^{2}=0.86\right)$, indicating that the increase in SOAfp was induced by higher levels of VOCs. The correlation between $\mathrm{PM}_{2.5}$ and SOA was strong during the whole observation period $\left(\mathrm{R}^{2}=0.54\right)$. As an important component of $\mathrm{PM}_{2.5}$, SOA had a positive correlation with $\mathrm{PM}_{2.5}$, which indicated that SOA had a key role in $\mathrm{PM}_{2.5}$ generation. Zhang et al. (2013) reported that the contribution of SOA to $\mathrm{PM}_{2.5}$ mass was greater during the polluted period (31\%) than during the clean period (6.82\%) in the urban sites of Beijing.

The source apportionment results revealed that industrial emission apportioned $26.26 \%$ of SOAfp contributors during the whole observation period (Fig. 6). Industrial emission $(28.62 \%)$ and solvent usage (37.07\%) were the main sources contributing to SOAfp in the pollution and clean periods, respectively. In contrast to the polluted period, the contribution of vehicle emission and industrial emission to SOAfp decreased from $27.88 \%$ to $14.32 \%$ and from $28.62 \%$ to $20.75 \%$ in the clean period, which may result from the limited traffic and factory closedown. Solvent usage increased from $18.38 \%$ to $37.07 \%$. Solvent usage was efficient to form SOA than other sources, which may include compounds with high reactivity that result in high SOAfp levels. In addition, the contribution of solvent usage to SOA was higher than that to VOCs. Thus, controlling the emission sources of solvent usage, vehicles, and industries can effectively reduce the SOAfp level during the polluted period.

\section{Health Risk Assessment of Aromatics}

As a standard to estimate the overall risk, 6 aromatics (benzene, toluene, ethylbenzene, $p$-xylene, $o$-xylene, and styrene) were characterized in health risk assessment. The HQ of non-cancer risk and carcinogenic risk (R) in the polluted period were $6.61 \times 10^{-2}$ and $5 \times 10^{-5}$, which were higher than those in the clean period $\left(2.20 \times 10^{-2}\right.$ and $2.85 \times$ $10^{-5}$ ), respectively. Benzene exhibited the maximum HQ and $\mathrm{R}$, attributing to its greater toxicity. The HQ of individual compounds did not exceed unity, but the HI value (2.3) indicated that cumulative exposure to these benzene series may cause potential non-carcinogenic risk to the public. $\mathrm{R}$ $\left(2.85 \times 10^{-5}\right.$ to $\left.5 \times 10^{-5}\right)$ of benzene was above the limit $(1 \times$ $10^{-6}$ ), indicating that benzene had a potential carcinogenic risk to health if the population had long-term exposure of benzene in the study area. Hence, benzene emission sources should be controlled for the exposed population health. Reducing benzene from some particular emission sources, such as the solvent usage and industrial emission, was quite important for public health.

\section{CONCLUSIONS}

To determine the variation of VOCs during different pollution periods in winter, VOC samples were passively analyzed in Yuncheng.

The VOC concentration averaged $87.66 \mu \mathrm{g} \mathrm{m}^{-3}$ across the entire observation period. The levels of alkanes, alkenes, alkynes, and aromatics were substantially higher during the polluted period, when particularly high proportions of alkanes $(61.04 \%)$ and aromatics $(22.84 \%)$ were found. The VOC concentration was 2.3 times higher during the polluted period than the clean period; furthermore, it was affected by meteorological conditions, such as wind speed or snowfall. Vehicle emission (30.04\%), coal combustion (21.56\%), and LPG/NG evaporation (19.46\%) were the dominant contributors of VOCs during the polluted period, which suggests that controlling these three factors would efficiently reduce VOCs.

Aromatics were the major precursors of the SOA. The source apportionment results revealed that solvent usage $(40.17 \%)$ and industrial emission $(30.37 \%)$ were the primary contributors to the SOAfp during the entire observation 


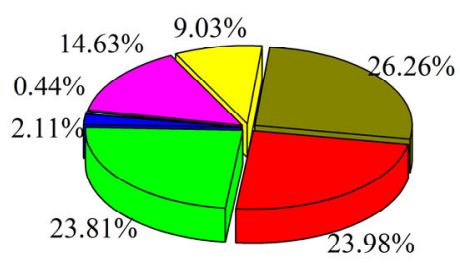

Whole observation

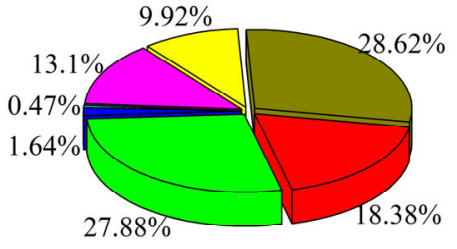

Polluted period

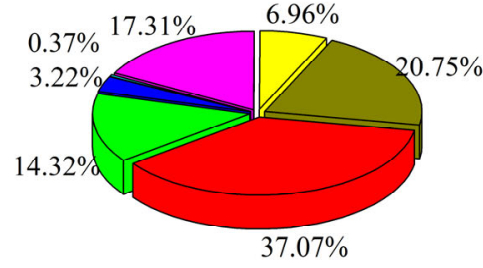

Clean period

\begin{tabular}{|c|c|c|c|}
\hline Solvent Usage & Vehicle emission & Biogenic emission & Gasoline evaporation \\
\hline Coal Combustion & LPG/NG & Industrial emission & \\
\hline
\end{tabular}

Fig. 6. The potential contribution of sources of VOCs in Yuncheng to SOA during different pollution periods.

period. Thus, controlling vehicle emission and solvent usage could effectively decrease the SOAfp during polluted periods.

Although the non-carcinogenic HQ was found to be acceptable, the HI value was 2.3 , indicating that cumulative exposure to the aromatics in this city potentially results in non-carcinogenic risks to the public. Additionally, benzene exceeded the permissible limit $\left(1 \times 10^{-6}\right)$ in terms of carcinogenic risk $\left(2.85 \times 10^{-5}\right.$ to $\left.5 \times 10^{-5}\right)$. Because aromatics are toxic substances as well as the major precursors of SOA, controlling solvent, vehicle, and industrial emissions will benefit public health and air quality.

In North China, large quantities of pollutants, including VOCs, are emitted due to the prevalence of coal combustion for heating during winter. However, the results of this study show that the contribution to VOCs from vehicle emission has surpassed that of coal combustion in Yuncheng, especially on heavily polluted days. A key factor has been the implementation of the "coal-to-gas" and "coal-to-electric" projects, which has reduced coal combustion during winter, and, based on the current policies, industrial restructuring will also decrease the contribution from this source (Yu et al., 2018). Therefore, to control VOC pollution in Yuncheng, a typical city in North China, it is necessary to strengthen the regulation of vehicle emissions in addition to maintaining the limits on coal combustion.

\section{ACKNOWLEDGMENTS}

This work was supported by grants from the National Natural Science Foundation of China (NSFC; No. 41673004), the National Key Research Program of China (No. 2016YFC0208500), and the Fundamental Research Funds for the Central Universities (2018ZD12).

\section{DISCLAIMER}

The authors declare that they have no known competing financial interests or personal relationships that could have appeared to influence the work reported in this paper.

\section{SUPPLEMENTARY MATERIAL}

Supplementary data associated with this article can be found in the online version at http://www.aaqr.org.

\section{REFERENCES}

An, J., Zhu, B., Wang, H., Li, Y., Lin, X. and Yang, H. (2014). Characteristics and source apportionment of VOCs measured in an industrial area of Nanjing, Yangtze River Delta, China. Atoms. Environ. 97: 206-214.

Barletta, B., Meinardi, S., Rowland, F.S., Chan, C.Y., Wang, X.M., Zou, S.C., Chan, L.Y. and Blake, D.R. (2005). Volatile organic compounds in 43 Chinese cities. Atoms. Environ. 39: 5979-5990.

Bruno, P., Caselli, M., de Gennaro, G., de Gennaro, L. and Tutino, M. (2006). High spatial resolution monitoring of benzene and toluene in the Urban Area of Taranto (Italy). J. Atmos. Chem. 54: 177-187.

Cai, C.J., Geng, F.H., Tie, X.X., Yu, Q.O. and An, J.L. (2010). Characteristics and source apportionment of VOCs measured in Shanghai, China. Atoms. Environ. 44: 5005-5014.

Chang, T., Wang, J.H., Lu, J.Q., Shen, Z.X., Huang, Y., Sun, J., Xu, H.M., Wang, X., Ren, D.X. and Cao. J.J. (2019). Evaluation of indoor air pollution during decorating process and inhalation health risks in Xi' an, China: A case study. Aerosol Air Qual. Res. 19: 854-864.

Cui, L., Wang, X.L., Ho, K.F., Gao, Y., Liu, C., Ho, S.S.H., Li, H.W., Lee, S.C., Wang, X.M., Jiang, B.Q., Huang, Y., Chow, J.C., Watson, J.G. and Chen, L.W. (2018). Decrease of VOC emissions from vehicular emissions in Hong Kong from 2003 to 2015: Results from a tunnel study. Atmos. Environ. 177: 64-74.

Deng, C.X., Jin, Y.J., Zhang, M., Liu, X.W. and Yu, Z.M. (2018). Emission characteristics of VOCs from on-road vehicles in an urban tunnel in eastern China and predictions for 2017-2026. Aerosol Air Qual. Res. 18: 3025-3034.

Dutta, C., Som, D., Chatterjee, A., Mukherjee, A.K., Jana, T.K. and Sen, S. (2009). Mixing ratios of carbonyls and BTEX in ambient air of Kolkata, India and their associated health risk. Environ. Monit. Assess. 148: 97107.

Eleonora, L.V., Francesco, F., Jgor, A., Umberto, G., Paolo, C., Martin, L.W. and Michela, M. (2016). Non-methane 
volatile organic compounds in the background atmospheres of a Southern European mountain site (Mt. Cimone, Italy): Annual and seasonal variability. Aerosol Air Qual. Res. 16: 581-592.

Fries, E., Sieg, K., Püttmann, W., Jaeschke, W., Winterhalter, R., Williams, J. and Moortgat, G. K. (2008). Benzene, alkylated benzenes, chlorinated hydrocarbons and monoterpenes in snow/ice at Jungfraujoch (46.6 N, 8.0 E) during CLACE 4 and 5. Sci. Total Environ. 391: 269-277.

Gao, J., Zhang, J., Li, H., Li, L., Xu, L., Zhang, Y., Wang, Z., Wang, X., Zhang, W., Chen, Y., Cheng, X., Zhang, H., Peng, L., Chai, F. and Wei, Y. (2018). Comparative study of volatile organic compounds in ambient air using observed mixing ratios and initial mixing ratios taking chemical loss into account - A case study in a typical urban area in Beijing. Sci. Total Environ. 628-629: 791804.

Grosjean, D. and John, H.S. (1989). Parameterization of the formation potential of secondary organic aerosols. Atoms. Environ. 23: 1733-1747.

Guo, S., Hu, M., Zamora, M.L., Peng, J.F., Shang, D.J., Zheng, J., Du, Z.F., Wu, Z., Shao, M., Zeng, L.M., Molina, M.J. and Zhang, R.Y. (2014). Elucidating severe urban haze formation in China. Proc. Natl. Acad. Sci. U.S.A. 111: 17373-17378.

Han, M., Lu, X.Q., Zhao, C.S., Ran, L. and Han, S.Q. (2015). Characterization and source apportionment of volatile organic compounds in urban and suburban Tianjin, China. Adv. Atmos. Sci. 32: 439-444.

Ho, K.F., Lee, S.C., Guo, H. and Tsai, W.Y. (2004). Seasonal and diurnal variations of volatile organic compounds (VOCs) in the atmosphere of Hong Kong. Sci. Total Environ. 322: 155-166.

Hu, B.Y., Xu, H., Deng, J.J., Yi, Z.G., Chen, J.S., Xu, L.L., Hong, Z.Y., Chen, X.Q. and Hong, Y.W. (2018). Characteristics and source apportionment of volatile organic compounds for different functional zones in a coastal city of southeast China. Aerosol Air Qual. Res. 18: 2840-2852.

Hui, L., Liu, X., Tan, Q., Feng, M., An, J., Qu, Y., Zhang, Y. and Jiang, M. (2018). Characteristics, source apportionment and contribution of VOCs to ozone formation in Wuhan, central China. Atmos. Environ. 192: 55-71.

Kumar, A., Singh, D., Kumar, K., Singh, B.B. and Jain, V.K. (2018). Distribution of VOCs in urban and rural atmospheres of subtropical India: Temporal variation, source attribution, ratios, OFP and risk assessment. Sci. Total Environ. 613: 492-501.

Lai, C.H., Chang, C.C., Wang, C.H., Shao, M., Zhang, Y.H. and Wang, J.L. (2009). Emissions of liquefied petroleum gas (LPG) from motor vehicles. Atoms. Environ. 43: 1456-1463.

Li, J., Zhai, C., Yu, J., Liu, R., Li, Y., Zeng, L. and Xie, S. (2018). Spatiotemporal variations of ambient volatile organic compounds and their sources in Chongqing, a mountainous megacity in China. Sci. Total Environ. 627: 1442-1452.

Li, L.Y., Xie, S.D., Zeng, L.M., Wu, R.R. and Li, J. (2015).
Characteristics of volatile organic compounds and their role in ground-level ozone formation in the BeijingTianjin-Hebei region, China. Atoms. Environ. 113: 247254.

Liu, B., Liang, D., Yang, J., Dai, Q., Bi, X., Feng, Y., Yuan, J., Xiao, Z., Zhang, Y. and Xu, H. (2016). Characterization and source apportionment of volatile organic compounds based on 1-year of observational data in Tianjin, China. Environ. Pollut. 218: 757-769.

Liu, B.S., Liang, D.N., Yang, J.M., Dai, Q.L., Bi, X.H., Feng, Y.C., Yuan, J., Xiao, Z.M., Zhang, Y.F. and Xu, H. (2016a). Characterization and source apportionment of volatile organic compounds based on 1-year of observational data in Tianjin, China. Environ. Pollut. 218: 757-769.

Liu, B.M., Wei Gong, W., Ma, Y.Y., Zhang, M., Yang, J. and Zhang, M. (2018). Surface Aerosol optical properties during high and low pollution periods at an urban site in central China. Aerosol Air Qual. Res. 18: 3035-3046.

Liu, Q., Wang, Y.S., Wu, F.K. and Sun, J. (2011). Observation and study on atmospheric VOCs in Changsha city. Environ. Sci. 32: 3543-3548.

Liu, Y., Shao, M., Fu, L.L., Lu, S.H., Zeng, L.M. and Tang, D.G. (2008). Source profiles of volatile organic compounds (VOCs) measured in China: Part I. Atmos. Environ. 42: 6247-6260.

Liu, Z.C., Li, N. and Wang, N. (2016b). Characterization and source identification of ambient VOCs in Jinan, China. Air Qual. Atmos. Health 9: 285-291.

Lokesh, K.S., Devendra, P., Ravi, Y. and Jaalnyam, M. (2016). Aromatic VOCs at major road junctions of a metropolis in India: Measurements using TD-GC-FID and PTR-TOF-MS instruments. Aerosol Air Qual. Res. 16: $2405-2420$

Lyu, X.P., Chen, N., Guo, H., Zhang, W.H., Wang, N., Wang, Y. and Liu, M. (2016). Ambient volatile organic compounds and their effect on ozone production in Wuhan, central China. Sci. Total Environ. 541: 200-209.

McCarthy, M.C., Aklilu, Y.A., Brown, S.G. and Lyder, D.A. (2013). Source apportionment of volatile organic compounds measured in Edmonton, Alberta. Atmos. Environ. 81: 504-516.

Na, K. and Kim, Y.P. (2001). Seasonal characteristics of ambient volatile organic compounds in Seoul, Korea. Atoms. Environ. 35: 2603-2614.

Na, K., Kim, Y.P., Moon, I. and Moon, K.C. (2004). Chemical composition of major VOC emission sources in the Seoul atmosphere. Chemosphere 55: 585-594.

Nelson, P.F. and Quigley, S.M. (1984). The hydrocarbon composition of exhaust emitted from gasoline fuelled vehicles. Atoms. Environ. 18: 79-87.

Norris, G., Duvall, R., Brown, S. and Bai, S. (2014). EPA Positive Matrix Factorization (PMF) 5.0 Fundamentals and User Guide. Washington, DC. EPA/600/R-14/108 (NTIS PB2015-105147).

Shao, P., An, J.L., Xin, J.Y., Wu, F.K., Wang, J.X., Ji, D.S. and Wang, Y.S. (2016). Source apportionment of VOCs and the contribution to photochemical ozone formation during summer in the typical industrial area in the 
Yangtze River Delta, China. Atmos. Res. 176: 64-74.

Song, C.B., Liu, B.S., Dai, Q.L., Li, H.R. and Mao, H.J. (2019a). Temperature dependence and source apportionment of volatile organic compounds (VOCs) at an urban site on the north China plain. Sci. Total Environ. 207: 167-181.

Song, M.D., Liu, X.G., Zhang, Y.H., Shao, M., Lu, K.D., Tan, Q.W., Feng, M. and Qu, Y. (2019b). Sources and abatement mechanisms of VOCs in southern China. Atmos. Environ. 201: 28-40.

Sun, J., Wu, F.K., Hu, B., Tang, G.Q., Zhang, J.K. and Wang, Y.S. (2016). VOC characteristics, emissions and contributions to SOA formation during hazy episodes. Atoms. Environ. 141: 560-570.

Wang, H.L., Jing, S.A., Lou, S.R., Hu, Q.Y., Li, L., Tao, S.K., Huang, C., Qiao, L.P. and Chen, C.H. (2017). Volatile organic compounds (VOCs) source profiles of on-road vehicle emissions in China. Sci. Total Environ. 607: 253-261.

Wang, Y., Ren, X., Ji, D., Zhang, J., Sun, J. and Wu, F. (2012). Characterization of volatile organic compounds in the urban area of Beijing from 2000 to 2007. J. Environ. Sci. 24: 95-101.

Wei, W., Li, Y., Wang, Y., Cheng, S. and Wang, L. (2018). Characteristics of VOCs during haze and non-haze days in Beijing, China: Concentration, chemical degradation and regional transport impact. Atmos. Environ. 194: 134 145.

Xu, H., Zhang, H., Xing, Z.Y. and Deng, J.J. (2015). Pollution characteristics and ozone formation potential of ambient VOCs in winter and spring in Xiamen. Environ. Sci. 36: 11-17.

Yan, Y.L., Peng, L., Cheng, N., Bai, H.L. and Mu, L. (2015). Health risk assessment of toxic VOCs species for the coal fire well drillers. Environ. Sci. Pollut. Res. Int. 22: 1513215144.

Yan, Y.L., Peng, L., Li, R.M., Li, Y.H., Li, L.J. and Bai, H.L. (2017). Concentration, ozone formation potential and source analysis of volatile organic compounds (VOCs) in a thermal power station centralized area: A study in Shuozhou, China. Environ. Pollut. 223: 295-304.

Yang, F., Yan, Y.L., Ge, Y.F., Li, R.M., Li, Y.H., Yu, H.L. and Peng, L. (2018). Characteristics and source apportionment of ambient volatile organic compounds in winter in Jincheng. Environ. Sci. 9: 4042-4050. (in Chinese)

Yang, W.Y., Li, J., Ming Wang, M., Sun, Y.L. and Wang,
Z.F. (2019). A Case study of investigating secondary organic aerosol formation pathways in Beijing using an observation-based SOA box model. Aerosol Air Qual. Res. 18: 1606-1616.

Yang, Y., Liu, X., Zheng, J., Tan, Q., Feng, M., Qu, Y., An, J. and Cheng, N. (2019). Characteristics of one-year observation of VOCs, $\mathrm{NO}_{x}$, and $\mathrm{O}_{3}$ at an urban site in Wuhan, China. J. Environ. Sci. 79: 297-310.

Yu, S.W., Zheng, S.H., Li, X. and Li, L.X. (2018). China can peak its energy-related carbon emissions before 2025: evidence from industry restructuring. Energy Econ. 73: 91-107.

Yuan, B., Shao, M., Lu, S.H. and Wang, B. (2010). Source profiles of volatile organic compounds associated with solvent use in Beijing, China. Atoms. Environ. 44: 19191926.

Zhang, G.Q., Wang, N., Jiang, X.J. and Zhao, Y. (2016). Characterization of ambient volatile organic compounds (VOCs) in the area adjacent to a petroleum refinery in Jinan, China. Aerosol Air Qual. Res. 17: 944-950.

Zhang, Y., Wang, X., Barletta, B., Simpson, I.J., Blake, D.R., Fu, X., Zhang, Z., He, Q., Liu, T., Zhao, X. and Ding, X. (2013). Source attributions of hazardous aromatic hydrocarbons in urban, suburban and rural areas in the Pearl River Delta (PRD) region. J. Hazard. Mater. 250-251: 403-411.

Zheng, C.H., Shen, J.L., Zhang, Y.X., Zhu, X.B., Wu, X.C., Chen, L.H. and Gao, X. (2017). Atmospheric emission characteristics and control policies of anthropogenic VOCs from industrial sources in Yangtze River Delta Region, China. Aerosol Air Qual. Res. 17: 2263-2275.

Zheng, G.J., Duan, F.K., Su, H., Ma, Y.L., Cheng, Y., Zheng, B., Zhang, Q., Huang, T., Kimoto, T., Chang, D., Poschl, U., Cheng, Y.F. and He, K.B. (2015). Exploring the severe winter haze in Beijing: the impact of synoptic weather, regional transport and heterogeneous reactions. Atmos. Chem. Phys. 15: 2969-2983.

Zheng, H., Kong, S., Xing, X., Mao, Y., Hu, T., Ding, Y., Li, G., Liu, D., Li, S. and Qi, S. (2018). Monitoring of volatile organic compounds (VOCs) from an oil and gas station in northwest China for 1 year. Atmos. Chem. Phys. 18: 4567-4595.

Received for review, August 21, 2019 Revised, November 4, 2019 Accepted, November 21, 2019 